\title{
Daraltılmış Treyler Şasi Tasarımı ve Sonlu Elemanlar Metodu ile Yapısal Analizi
}

\author{
Tayfun ÖZGÜR*1, Seyfi Burak KARATAŞ² \\ ${ }^{1}$ Çukurova Üniversitesi, Mühendislik Fakültesi, Otomotiv Mühendisliği Bölümü, Adana \\ ${ }^{2}$ Makinsan Treyler San. ve Tic. Ltd. Şti. Acıdere OSB, Adana
}

Geliş tarihi: 15.02.2021 Kabul tarihi: 31.03 .2021

\section{$\ddot{O} z$}

Otomotiv sektöründe taşımacılıkta treyler tipi ağır vasıtalar büyük öneme sahiptir. Ülkemizde gerek kullanım alanının geniş olması gerekse de ekonomik ve tecrübeli servis hizmetlerinin bulunması ile damperli treyler tipi taşıtlar daha çok tercih edilmektedir. Damperli treyler tipi araçların ağırlığının büyük oranını şasi oluşturmaktadır. Treyler şasisi dinamik ve statik birçok kuvvete maruz kalmaktadır. Bu sebeplerden treyler üreticileri tarafından da öncelikli çalışma konusu olarak şasi tercih edilmektedir. Bu çalışmada bir treyler şasisinin enine uzunluğu dar yapıda yeniden modellenerek yapısal analizinin eski modeli ile karşılaştırılması amaçlanmaktadır. Bu yeni dar yapıda tasarım, DIN standartlarında belirtilen aks yay merkezleri arası mesafe dikkate alınarak oluşturulmuştur. Mukavemet değerleri korunarak dar yapıda, daha hafif, yakıt ve çevre dostu yeni bir treyler tasarlamak bu çalışmanın ana hedefini oluşturmaktadır. $\mathrm{Bu}$ çalışmadaki analiz ve hesaplamalar göstermektedir ki; dar yapıda modellenen treylerin $\% 7$ oranında ağırlığında bir azalma meydana gelmiştir. Sonuç olarak, ağırlık azaltımının sağladığ 1 yakıt tasarrufu sayesinde daha çevreci bir treyler tasarımı elde edilmiştir.

Anahtar Kelimeler: Treyler, Damper, Şasi, Aks yayı, Dar yapı

\section{Design of Narrowed Trailer Chassis and Structural Analysis with Finite Element Method}

\begin{abstract}
Trailer-type heavy vehicles are of great importance in transportation in the automotive sector. Dumper trailer type vehicles are preferred more with their usage area as well as economical and experienced service in our country. A large proportion of the weight of the tipper trailer type is the chassis. The chassis of the trailer is exposed to many dynamic and static forces. For these reasons, it is preferred by the chassis trailer manufacturers also as a priority work subject. In this study, it is aimed to remodel the transverse length of a trailer chassis with a narrow structure and compare the structural analysis with the
\end{abstract}

*Sorumlu Yazar (Corresponding author): Tayfun ÖZGÜR, tozgur@cu.edu.tr 
old model. In this new narrow structure, the design is based on the distances between the axle spring centers specified in DIN standards. Designing a narrow, lighter, fuel, and environment-friendly new trailer by protecting the strength values is the main purpose of this study. The analysis and calculations in this study show that; there has been a $7 \%$ reduction in the weight of the trailer modeled in a narrow structure. As a result, a more environmentally friendly trailer design has been achieved thanks to the fuel savings provided by weight reduction.

Keywords: Trailer, Dumper, Chassis, Axle spring, Narrow structure

\section{GÍRİS}

Son yıllarda kirletici gazların meydana getirdiği çevre kirliliğinin önüne geçebilmek, yakıt tasarrufu sağlamak ya da üretim maliyetini azaltma çabaları neticesinde taşıt ağılıklarının azaltılması çalışmaları giderek önem kazanmaktadır. Özellikle elektrikli ve hibrit taşıtlar gibi yeni konseptlerin hafif konstrüksiyon üzerine kurgulanmış olmasıyla bu önemi daha da artırmaktadır. Taşıt hafifletme çalışmaları ile birlikte taşıtların hızlanması ya da yokuş çıkması için gereken enerji miktarı azaltılabilmekte buna ek olarak taşıtın yavaşlatılması ya da durdurulması sırasında fren kuvveti ile birlikte sürtünmeyle kaybolan enerji daha da aza indirilebilmektedir. Sonuç olarak yakıt ekonomisine katk1 enerjinin korunumu ile sağlanmaktadır [1].

Emisyonlar üzerinde önemli olumlu etkileri bulunan hafifletme çalışmaları ile Dünyadaki $\mathrm{CO}_{2}$ (karbondioksit) emisyonlarının oluşumunun azaltılması arasında bir ilişsi söz konusudur. Günümüzde dünya genelinde oluşan $\mathrm{CO}_{2}$ emisyonlarının yaklaşık \%20'si taşıtlardan kaynaklanmaktadır. Artan dünya nüfusu ile bu oranın ilerleyen yıllarda daha da artacağı beklenmektedir. Bu durum göz önüne alındığında gerek regülasyonlar gerekse de yasalar ile emisyonların daha sıkı bir şekilde kontrol edilmesi gerekliliği ortaya çıkacaktır. Bu nedenlerle adına emisyonların azaltılmasına katkı sağlamak, tasarımcılar için önemli kriterden biridir. Emisyonları azaltmak için yapılan çalışmalar örnek olarak; taşııllarda yüksek mukavemetli çelik kullanımı gösterilebilir. Gelişmiş yüksek mukavemetli çelikler (Advanced High Strength
Steel-AHSS) ile yapılan üretim ile bir taşıtın ömrü boyunca çevreye bıraktığı $\mathrm{CO}_{2}$ miktarında yaklaşık 2800 kg'llk bir azalma sağlamak mümkün olabilmektedir. $\mathrm{Bu}$ kazanımların $460 \quad$ kg'llk bölümü malzemelerin üretimi esnasında sağlanırken geri kalan 2340 kg'lık bölümü ise taşıtların kullanılması esnasında sağlanmaktadır. Şekil 1'de $\mathrm{CO}_{2}$ emisyon miktarındaki değişim yıllara göre gösterilmiş olup grafikte yer alan azalma eğilimi görülmektedir.

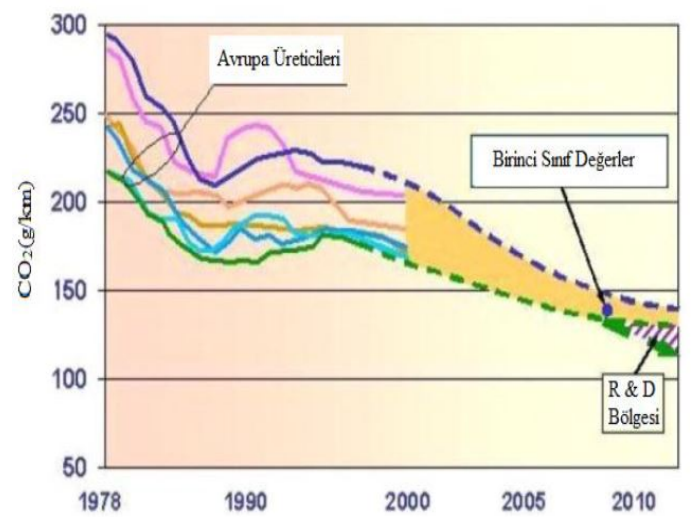

Şekil 1. Taşıtlardaki $\mathrm{CO}_{2}$ emisyon miktarının yıllara göre değişimi [2]

Otomotiv sektöründe taşımacılıkta treyler tipi ağır vasıtalar büyük öneme sahiptir. Ülkemizde gerek kullanım alanının geniş olması gerekse de ekonomik ve tecrübeli servis hizmetlerinin bulunması ile treyler tipi taşıtlar daha çok tercih edilmektedir. Treyler tipi araçların ağırlı̆̆ının büyük oranını şasi oluşturmaktadır. Treyler şasisi dinamik ve statik birçok kuvvete maruz kalmaktadır. $\mathrm{Bu}$ sebeplerden dolayı treyler üreticileri tarafından da öncelikli çalışma konusu olarak şasi tercih edilmektedir. 
Büyük Britanya Ulaştırma Bakanlığı tarafindan 2010 yılında yapılan bir çalışmaya göre, ağır yük taşıtları (ağır vasıtalar) Büyük Britanya'daki toplam yük hareketlerinin, toplam ton kilometrelerin \%68'ini ve taşınan toplam tonların \%82'sini oluşturmaktadır [3]. Tahminler, karayolu taşımacılığı faaliyetinin hem toplum hem de ekonomi için temel önemde olmaya devam edeceğini göstermektedir [4]. Ancak karayolu yük taşımacılığı, İngiltere'nin karbon ayak izinin yaklaşık \%5'ini oluşturduğu için çevre üzerinde olumsuz bir etkiye sahiptir [3]. Birleşik Krallık hükümeti tarafindan belirlenen yeni hedefler doğrultusunda 2050 yılına kadar $\mathrm{CO}_{2}$ emisyonlarında 1990 seviyelerine kıyasla \%80 oranında bir azalma hedeflenmektedir.

Şekil 2'de emisyon çeşitlerinin yalnızca taşıt ağırlığına bağlı olarak değişimi görülmektedir. Taşıt yarı doluyken ve boşken yapılan kıyaslama ile emisyonlar ve yakıt tüketiminin ağırlıkla olan ilişkisi ortaya koyulmuştur [2].

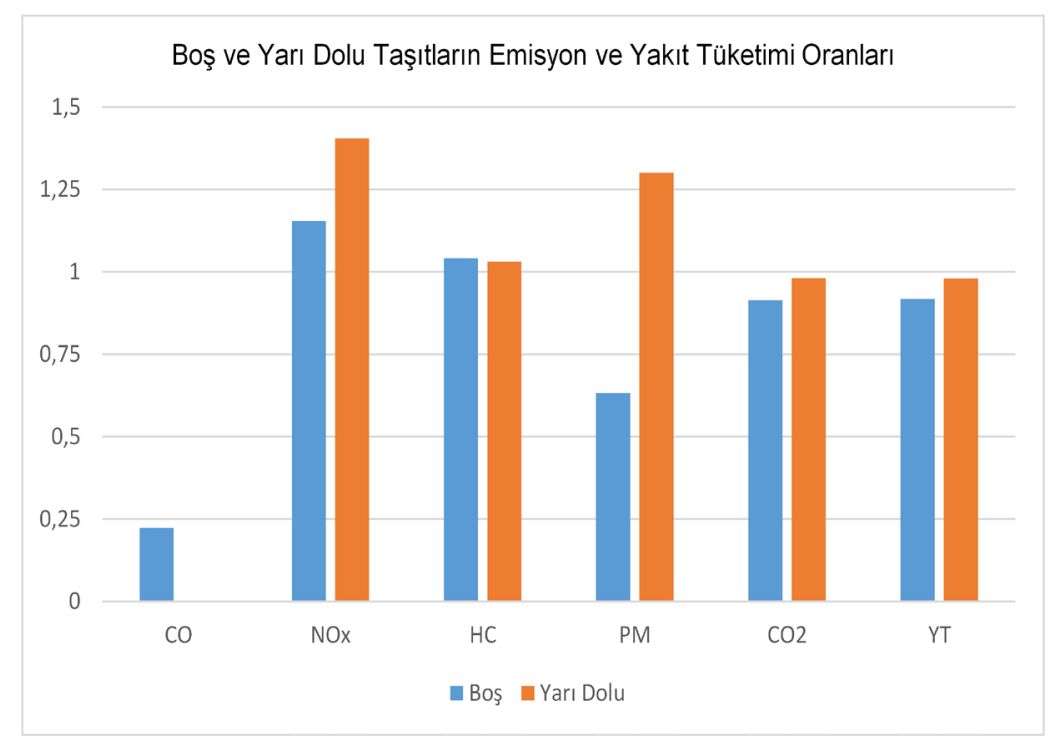

Şekil 2. Boş ve yarı dolu taşıtın emisyon ve yakıt tüketim oranları [2]

Toplam boş araç ağırlığı, araç yakıt tüketimine ve $\mathrm{CO}_{2}$ emisyonlarına katkıda bulunan faktörlerden birisidir. Mafsallı karayolu yük taşıtlarının toplam boş ağırlığı, çekicinin boş ağırlığı ile römorkun boş ağırlığının birleşimden oluşmaktadır. $\mathrm{Bu}$ nedenle, treylerin boş kütlesinin azaltılmasıyla aracın bir bütün olarak enerji verimliliği iyileştirilebilmektedir [5].

Ağır vasıtaların enerji tüketimine katkıda bulunan ana unsurlar üç geniş kategoriye ayrılabilir:

1. Araç tasarım faktörleri; araç boyutları, kütle, hacim, motor verimi, yuvarlanma direnci, aerodinamik gibi profil ve malzeme seçimi.
2. Lojistik faktörler; araç kullanımı, araç hızı, araç rotası ve tedarik zinciri yapısı gibi.

3. D1ş faktörler; sürüş döngüsü, trafik koşulları, sürücü davranışı ve hava koşulları gibi.

Ayrıca treylerin yüksüz kütlesini $\% 25$ azaltarak yakıt tüketiminde yaklaşık \%6,5'lik bir azalma bekleneceği de belirtilmiştir. Bununla birlikte, hafifletme nedeniyle yakıt tüketiminde tahmini \%6,5'lik azalma, ekolojik denge için oldukça önemlidir ve diğer önlemlere kıyasla daha kolay uygulanabilirliği bulunmaktadır. Aslında, treylerin yüksüz kütlesinin azaltılmasının, muhtemelen uygulanacak araç tasarım değişikliklerinin en kolay yolu olduğu öne sürülmüştür [6]. Bununla birlikte, Britanya hükümetinin iddialı 2050 
emisyon azaltma hedefine ulaşmak için bir önlem portföyüne ihtiyaç duyulacağı unutulmamalıdır [5]. Bu tür önlemler şunları içerebilir: Léonardi ve Baumgartner tarafindan önerilenler gibi treyler hafifletme, geliştirilmiş treyler aerodinamiği, alternatif yakıtların benimsenmesi ve araç kullanımını iyileştirmek için girişimler [7]. Sürücü eğitimi ve ödül programlarının yakıt tüketimini azaltmada değerli olduğu gösterilmiştir [8]. Uzun vadeli sera gazı emisyonlarında iddialı düşüşler elde etmek için bir çözüm portföyüne duyulan ihtiyaç, literatürde iyi belirtilmiştir [9].

Tasarımda hafif malzemelerin uygulanmasıyla boş treyler kütlesini azaltma fikri yeni bir fikir değil ve son on yil boyunca bunu yapmanın potansiyel faydaları giderek artan bir şekilde değerlendirilmiştir. $\mathrm{Bu}$, nihayetinde yapılarında hafif kompozit malzemeler kullanan bir dizi hafif treyler prototipinin geliştirilmesine yol açmıştır [6]. Bu tür hafif treyler örnekleri arasında ROADLITE Treyler, CleanMould Treyler, Composittrailer, Phoenixx Treyler ve Walmart Prototip Treyler bulunmaktadir [10-14]. Karbon fiber bazlı soğutmalı Aldi treyler gibi soğutmalı treylerlere hafif malzemeler de uygulanmıştır [15]. $\mathrm{Bu}$ projelerin tümünde, geleneksel çelik römorklara kıyasla boş treyler ağırlığı \%10 ila \%30 oranında azaltması sonucuna başarılı bir şekilde ulaşılmıştır [6]. Galos ve Sutcliffe [16] yaptıkları çalışmada, yapısal optimizasyon ve malzeme seçimi kombinasyonun hafif kamyon römorku üzerinde incelemesi yapmışlardır. Geliştirilen sonlu eleman modeli ve malzeme optimizasyonu ile ağırlıktan \%67 (1326 kg) tasarruf edilebileceğini göstermiştir. Bir diğer çalışmada ise Galos ve arkadaşları [5] iki ayrı firmaya ait yüreyen zeminli iki treylerin ağırlık azaltımından nasıl etkilendiğini istatiksel olarak incelemişlerdir. Treylerlerin boş ağırlığının \%30 azaltılmasının, treylerler için \%11 kütle enerji performans azalması sonucuna ulaşmışlardır.

Dünyadaki otomotiv ve taşımacılık sektörü taşıyabilecekleri maksimum yükü Karayolları istiap haddini aşmadan güvenli bir taşıma amacında olup aynı zamanda bu işlemi minimum yakıt tüketimi ile başarmak isteğindedir. Böylece çevreye zararlı emisyon salınımı azaltılacak, çevre dostu araçlar üretilebilecektir [17].

Yarı römork üreticileri bu durumu göz önünde bulundurarak çalışmalarını öncelikle yük transferindeki temel öge kabul edilen şasi üzerinde yoğunlaştırmışlardır.

$\mathrm{Bu}$ çalışma bir treyler şasisinin daha hafif yapıda yeniden modellenmesi ve yük dayanımının eski model ile karşılaştırılması sonucu daha ergonomik treyler ürünü ortaya çıkarılması hedeflenmektedir. Ayrıca, mukavemet değerleri korunarak yeni bir form verilen, daha hafif, yakıt ve çevre dostu yeni bir treyler tasarlamak bu çalışmanın ana hedefini oluşturmaktadır. Yeni tasarımla birlikte karayolları istiap haddi kısıdıyla aracına belirli miktarda yük yüklemenin yanında kullanıcıların güvenle tercih edeceği çevre dostu hafif formda araç ihtiyacı karşılanmış olacaktır.

\section{MATERYAL VE YÖNTEM}

\subsection{Materyal}

$\mathrm{Bu}$ çalışmaya konu olan treyler şasisi de çoğunlukla St52 yerine S700MC gibi yüksek mukavemetli çelik sac malzemelerden oluşmaktadır. St52 ve S700MC çelikleri için alaşım elementlerinin yüzdesi karşılaştırıldığında, S700MC çeliğinin, malzemelerin mekanik özelliklerini artıran bazı temel alaşım bileşenlerinin daha fazla yüzde oranına sahip olduğu görülmektedir. Örneğin, S700MC, mukavemeti ve sertliği artıran \%55 daha yüksek manganeze (Mn) mukavemeti, sertliği, aşınma direncini ve korozyon direncini artıran \%675 daha yüksek kroma $(\mathrm{Cr})$ ve tokluğu ve sertleşebilirliği artıran \%3920 daha fazla molibdene (Mo) sahiptir. $\mathrm{Bu}$ temel alaşım elementleri aynı zamanda daha iyi sertlik ve aşındırıcı aşınma direnci için karbür oluşturan elementlerdir [18].

Yeni modellenen tasarımda Alman Standartlar Enstitüsü (DIN-Deutches Institut Für Normung) standartları temel alınarak aks makas merkezleri arası mesafe 1300 mm'den 1200 mm'ye 
çekilmiştir. Ayrıca şaside kullanılan diğer parçalar da bu ölçü temel alınarak kısaltılmıştır.

Araç ağırlığının büyük oranını oluşturan, dinamik ve statik kuvvetlere direkt maruz kalan I kesitli S700MC malzemeden üretilecek şasinin dayanımını koruyarak darbelere ve hava sürükleme kuvvetine daha az maruz kalacak hafif ve doğaya en az zarar verecek daraltılmış formda yeni bir tasarıma ihtiyaç duyulmuştur.

\subsubsection{Ticari Araç Kataloğu 2010/2011 (DIN Standartlarına Göre)}

Modeli şekillendirirken referans alınan önemli çıkış noktalarından biri ağır vasıta araçlarında kullanılan aksların teknik özelliklerinin ve toleranslarının dışına çıkmadan makas merkezlerini değiştirebilme düşüncesidir. DIN standartlarına göre aks teknik özellikleriyle birlikte makas merkez uzunlukları tolerans aralıkları aşağıda Çizelge 1'de verilmiştir.

$\mathrm{Bu}$ çizelge, DIN Standartları temel alınarak Avrupa'da bir aks üreticisi firmanın ağır ticari araçlar için kullanılacak aksların teknik detaylarını belirttiği ürün kataloğundan alınmıştır. Bu bilgilere göre 3 Akslı Damperli Treyler'de kullanılan aks modelinin makas merkezlerinin ayarlanabileceği mesafelerin tolerans aralıkları verilmiştir (1300 mm> $1200 \mathrm{~mm})$ [19].

Çizelge 1. Aks makas yayı merkezleri arası mesafe [19]

\begin{tabular}{|c|c|c|c|c|c|c|c|}
\hline Aks tipi & $\begin{array}{c}105 \mathrm{~km} / \mathrm{saatte} \\
\text { izin verilen } \\
\text { yük } \\
\text { kapasitesi } \\
\text { (kg) } \\
\end{array}$ & $\begin{array}{c}\text { İz } \\
\text { genişliği } \\
\text { (SP) } \\
(\mathbf{m m})\end{array}$ & $\begin{array}{c}\text { Yay } \\
\text { merkezi } \\
(\mathrm{FM}) \\
(\mathrm{mm})\end{array}$ & $\begin{array}{c}\text { Aks } \\
\text { kesiti } \\
(\mathbf{m m})\end{array}$ & Lastik örneği & $\begin{array}{c}\text { Toplam } \\
\text { genişlik } \\
\text { (P) } \\
(\mathrm{mm})\end{array}$ & $\begin{array}{c}\text { Aks } \\
\text { ağ̀rlığ̀ } \\
\text { (kg) }\end{array}$ \\
\hline HSF 6510 & 6500 & 2040 & 1300 & $120 \times 10$ & 10 R20 & 2335 & 280 \\
\hline HSF 6508 & 6500 & 2040 & 1300 & $120 \times 10$ & 10 R20 & 2340 & 278 \\
\hline HSF 9010 & 9000 & 2095 & 1300 & $120 \times 10$ & $385 / 65$ R22.5 & 2490 & 292 \\
\hline HSF 9010 & 9000 & 2140 & 1400 & $120 \times 10$ & $385 / 65$ R22.5 & 2535 & 294 \\
\hline HSF 9010 & 9000 & 2140 & 1400 & $120 \times 10$ & $385 / 65$ R22.5 & 2535 & 295 \\
\hline HSF 9010 & 9000 & 2040 & 1200 & $120 \times 10$ & $385 / 65$ R22.5 & 2435 & 328 \\
\hline HSF 9010 & 9000 & 2040 & 1300 & $120 \times 10$ & $385 / 65$ R22.5 & 2435 & 328 \\
\hline HZF 10110 & 11000 & 1820 & 900 & $150 \times 10$ & $11 \mathrm{R} 22.5$ & 2425 & 352 \\
\hline HZF 10110 & 11000 & 1820 & 980 & $150 \times 10$ & 11 R22.5 & 2425 & 352 \\
\hline HSF 12010 & 12000 & 2040 & 1300 & $150 \times 10$ & $445 / 65$ R22.5 & 2505 & 385 \\
\hline
\end{tabular}

\subsection{2. Şasi Tasarımı}

Önceki bölümlerde incelenen veriler 1şı̆̆ında aracı, etkiyen teknik aksesuarların konumları da göz önüne alınarak yapılan tasarım çalışmaları sonucunda $100 \mathrm{~mm}$ daha dar yapıda tasarlanmıştır. Bu bağlamda etkilenen ve yeniden modellenen şasi parçaları; ara taşıyıcılar, king pim tablası grubu, park ayağı braketi, arka mil ve arka tampon grubudur.

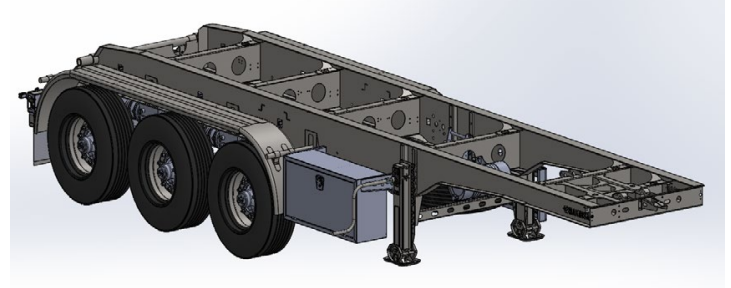

Şekil 3. Komple şasi 
Yeni form kazandırılan şasi, standart üst yapıya uygun olarak 8,6 metre uzunluğunda, boyuna taşıyıcı ayna sacları arası mesafe $1195 \mathrm{~mm}$ ve değiştirilen metal gruplarının $917 \mathrm{~kg}$ olacak şekilde modellenecek şekilde tasarlanmıştır.

\subsection{Yöntem}

Yeni ve eski formdaki şasi modellerine sonlu elemanlar metodu ile statik analiz uygulanmış ve sonuçları karşılaştırılmıştır.

\subsubsection{Aks Modelinin Sonlu Elemanlar Metodu ile Statik Analizi}

Aksların sonlu elemanlar metodu ile statik analizinde en doğru sonucu verecek kalitede mesh uygulanmıştır. Denemeler sonucunda \%100 uygunluk (relevance), $7 \mathrm{~mm}$ mesh eleman boyutu kullanılarak en iyi ve gerçekçi sonuca yaklaşılmıştır. Sonlu elemanlar metodu ile yapılan analizlerde mesh yani modeli elemanlarına ayırma yöntemi kullanılmaktadır.

\begin{tabular}{|c|c|c|}
\hline \multicolumn{3}{|c|}{ Details of "Mesh" } \\
\hline \multirow[t]{2}{*}{$\square$} & \multicolumn{2}{|l|}{ Display } \\
\hline & Display Style & Body Color \\
\hline \multirow[t]{4}{*}{$\square$} & \multicolumn{2}{|l|}{ Defaults } \\
\hline & Physics Preference & Mechanical \\
\hline & $\square$ Relevance & 100 \\
\hline & Element Order & Program Controlled \\
\hline \multirow[t]{10}{*}{$\square$} & \multicolumn{2}{|l|}{ Sizing } \\
\hline & Size Function & Adaptive \\
\hline & Relevance Center & Coarse \\
\hline & $\square$ Element Size & $7,0 \mathrm{~mm}$ \\
\hline & Initial Size Seed & Assembly \\
\hline & Transition & Fast \\
\hline & Span Angle Center & Coarse \\
\hline & Automatic Mesh Based Defeaturing & On \\
\hline & $\square$ Defeature Size & Default \\
\hline & Minimum Edge Length & $2,9872 \mathrm{e}-002 \mathrm{~mm}$ \\
\hline \multirow[t]{10}{*}{$\Theta$} & \multicolumn{2}{|l|}{ Quality } \\
\hline & Check Mesh Quality & Yes, Errors \\
\hline & Error Limits & Standard Mechanical \\
\hline & $\square$ Target Quality & Default $(0.050000)$ \\
\hline & Smoothing & Medium \\
\hline & Mesh Metric & Skewness \\
\hline & $\square$ Min & $1,3057 e-010$ \\
\hline & $\square \operatorname{Max}$ & 0,99971 \\
\hline & $\square$ Average & 0,26302 \\
\hline & Standard Deviation & 0,18827 \\
\hline
\end{tabular}

Şekil 4. Ağ detayları
$\mathrm{Bu}$ adımda en iyi sonuca varabilmek için en kaliteli meshi uygulamak gerekmektedir [20].

En yaygın kullanılan ve gerçeğe yakın sonuç veren mesh kalite kriteri skewness yani eğrilik tabanlı mesh kalite kriteridir. Bu analizin mesh detaylarına da Şekil 4'te görüldüğü gibi seçilen eleman sayısı $7 \mathrm{~mm}$, ortalama eğrilik kalite değeri (average of skewness) 0,26 olarak ayarlanmıştır. Skewness değeri hesaplanmasında aşağıdaki eşitlik kullanılmaktadır.

Skewness $=\frac{O \cdot E \cdot B \cdot-A \cdot E \cdot B .}{O \cdot E \cdot B \cdot}$

O.E.B.: Optimum Element Boyu

A.E.B.: Aktif Element Boyu

Çizelge 2. Skewness mesh kalite kriterleri [21]

\begin{tabular}{|c|l|}
\hline Skewness mesh değeri & \multicolumn{1}{c|}{ Kalite kriteri } \\
\hline $0-0,25$ & Mükemmel \\
\hline $0,25-0,50$ & Çok iyi \\
\hline $0,50-0,80$ & İyi \\
\hline $0,80-0,94$ & Uygun \\
\hline $0,94-0,97$ & Kötü \\
\hline $0,98-1$ & Kabul edilemez \\
\hline
\end{tabular}

Şekil 5'te aksa uygulanan mesh görseli yer almaktadır.

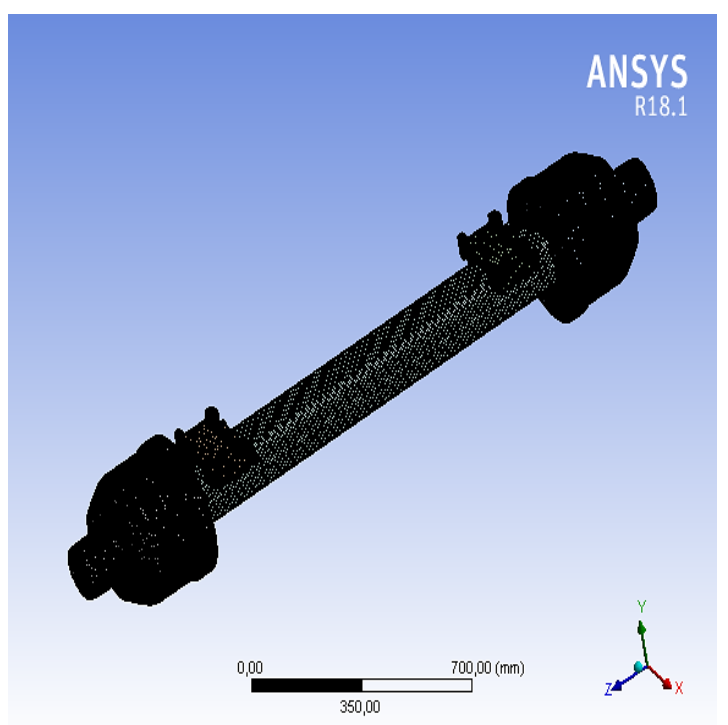

Şekil 5. Aksa uygulanan mesh modeli 
Aks üreticisinden alınan teknik tedarikçi kataloğundaki bilgilere göre kullanılan aks kapasiteleri $9000 \mathrm{~kg}$ olarak belirtilmiştir. Aks makas yay merkezleri $100 \mathrm{~mm}$ kısaltılarak (1300 mm>1200 mm) modellenmiştir. Sonlu elemanlar metodu ile uygulanan yapısal analizde aks emniyet katsayısı 2 alınarak $9000 \mathrm{~kg}$ × $2=$ $18000 \mathrm{~kg}=176580 \mathrm{~N}$ yayılı yük atanmıștır.

Aks makas tablalarından uygulanan kuvvet ve tepki kuvvet noktaları Şekil 6'daki gibi makas merkezleri ve aks kafası olarak atanmıştır.

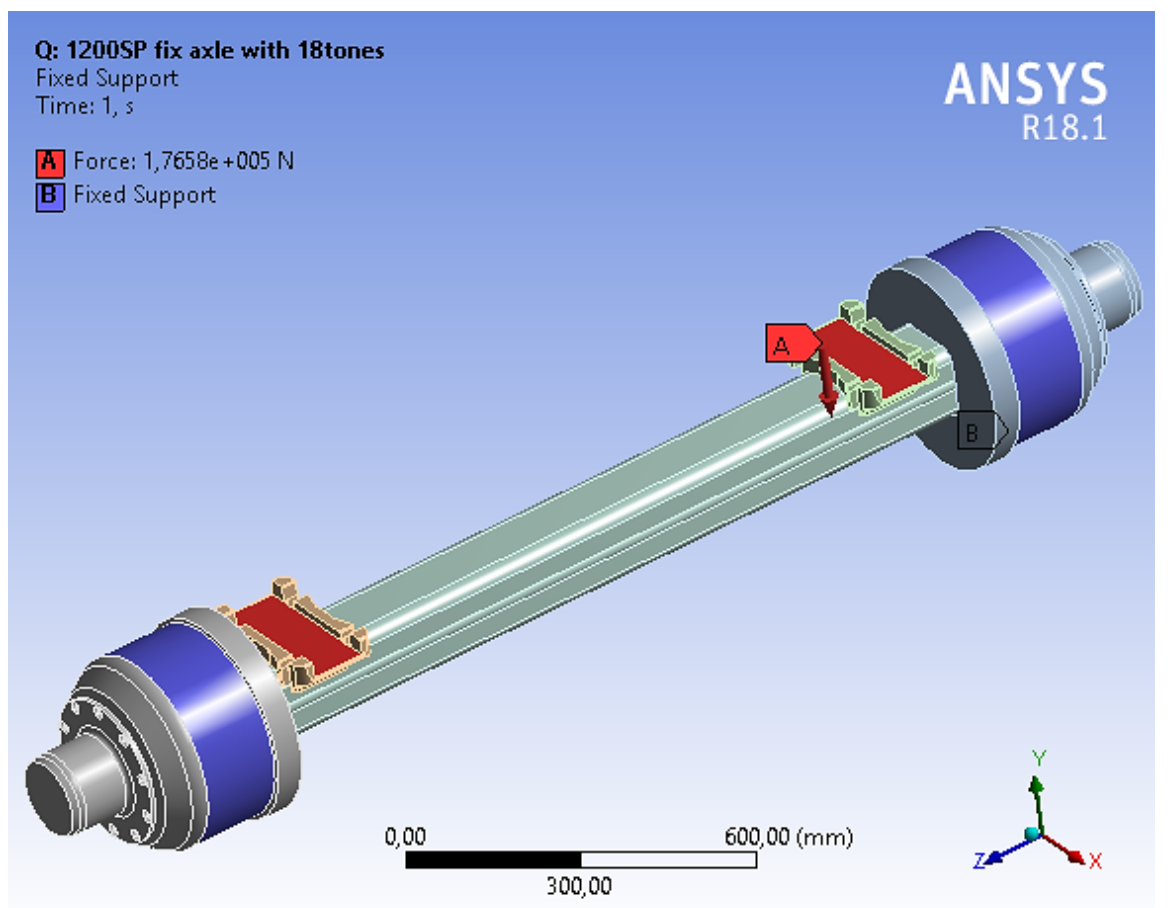

Şekil 6. Aks modeline uygulanan yük ve sabit destek noktaları

\subsection{2. Şasi Modelinin Sonlu Elemanlar Metodu ile Statik Analizi}

Ulaşılabilecek en iyi sonuçları elde etmek için, denemeler sonucunda en gerçekçi analize ve modele uygun mesh uygunluk (relevance) oranı \%94 olarak atanmıştır. $\mathrm{Bu}$ analizde ortalama eğrilik kalite değeri 0,71 olarak ayarlanmıştır.

Uygulanacak kuvvet, Şekil 7'de görüldüğü gibi üst yapının montajlanacağı şasi üst lama yüzeylerinde, destek noktaları ise taşınacak yüke tepki gösterecek aks ve king pimi bölgelerinde seçilmiştir.

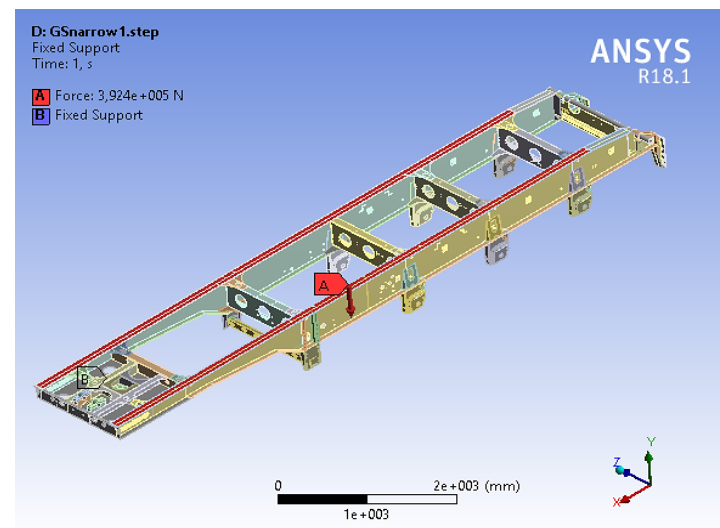

Şekil 7. Şasi modeline uygulanan yük ve sabit destek noktaları 


\section{BULGULAR}

Sonlu elemanlar metodu ile aks modelinin uygulanan analiz ile 18000 kg'lık sanal yüke karşı tepkisi ölçülmüştür.

Makas yay merkezleri mesafe $1200 \mathrm{~mm}$ olan yeni aks modelinin $1300 \mathrm{~mm}$ olan modelden deformasyon değeri \%35, maksimum gerilim değeri bazında da \%1 oranında daha fazla çıkmasına karşın dayanıklı ve emniyetli koşullarda çalışmaya uygundur.
Maksimum deformasyon yeni modelde aks gövdesinde, eski aks modelinde ise makas tablalarında gözlenmektedir. Maksimum gerilimin oluştuğu bölge ise her iki modelde de makas tablası üzerinde gözlenmektedir. Şekil 9'daki eski aks modelinde meydana gelen maksimum gerilim değerinden çok az bir oranda fazla çıkmış olsa da Şekil 8'den ulaşılan yeni modellenen aks grubunun analiz sonucunda maruz kaldığı gerilim değeri (148.91 MPa), aks malzemesinin verilen dayanabileceği maksimum gerilim değerinin (355 MPa) yalnızca \%42'sine karşılık gelmektedir.

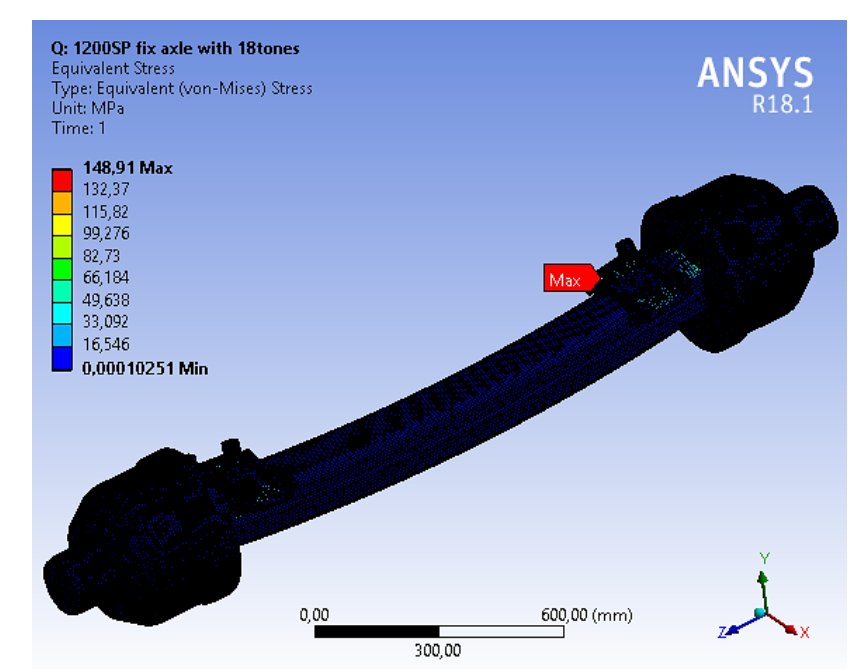

Şekil 8. $1200 \mathrm{~mm}$ yay merkez mesafeli aks modelinde meydana gelen gerilim değeri

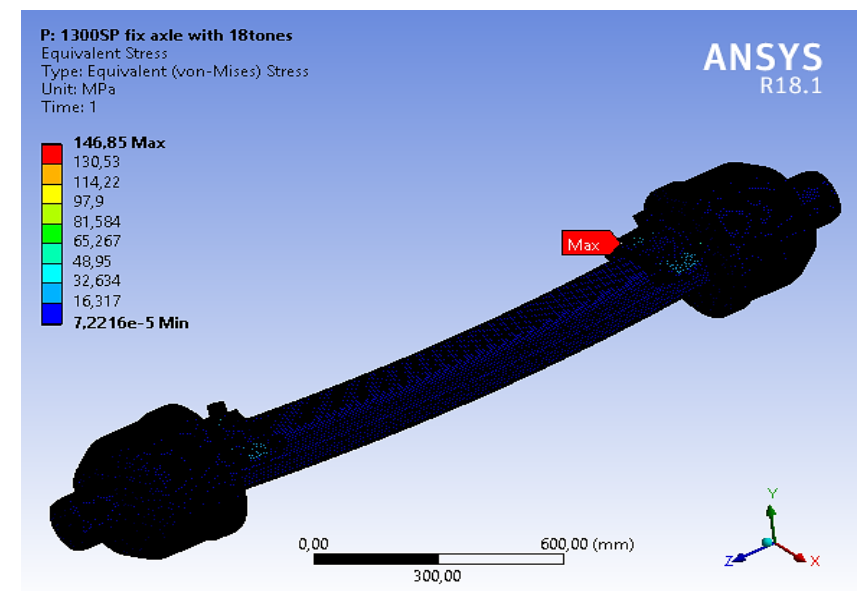

Şekil 9. $1300 \mathrm{~mm}$ yay merkez mesafeli aks modelinde meydana gelen gerilim değeri 
Aks üretiminde kullanılan S355 malzemenin akma dayanımı (355 $\mathrm{MPa})$ dikkate alınarak, emniyet katsayısı 2 seçilerek $18000 \mathrm{~kg}$ yük altında teorik olarak mukavim olmakla birlikte emniyetli çalışacağı yorumu yapılabilmektedir.
Maksimum deformasyon, yeni şasi modelinde Şekil 10, eski şasi modelinde Şekil 11'de görüldüğü gibi şasi boyun kısmı ile ön ara taşıyıcı arasında gözlenmektedir. Maksimum gerilimin oluştuğu bölge ise king pim tablası ile şasi üst laması kesişim bölgesinde gözlenmektedir.

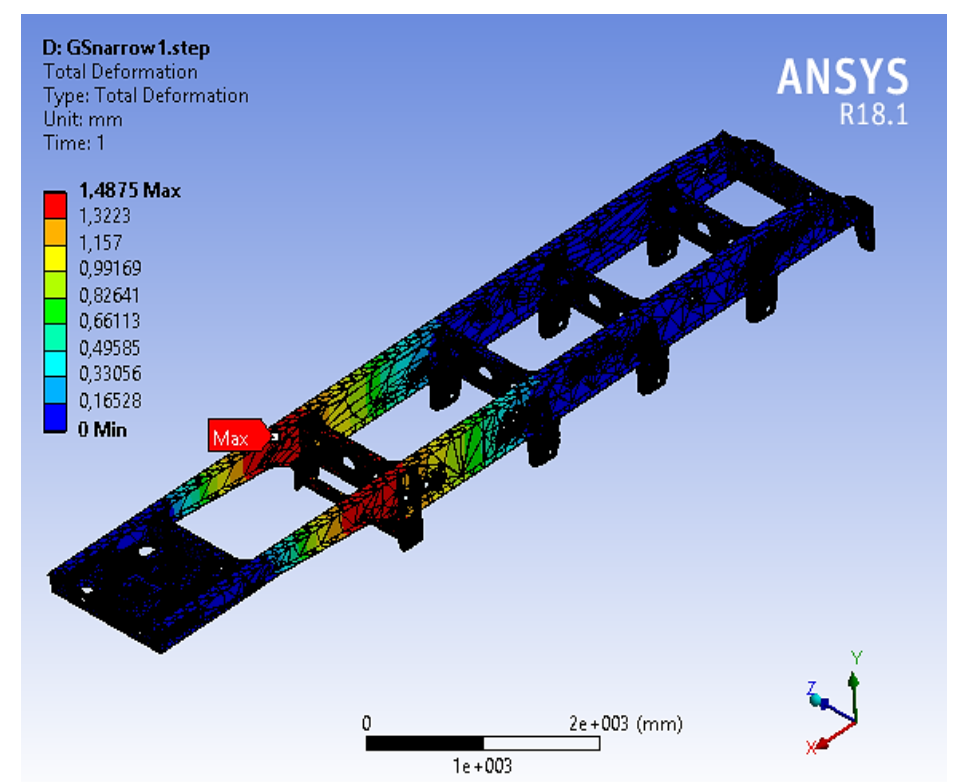

Şekil 10. Daraltılmış şasi modelinde meydana gelen deformasyon değeri

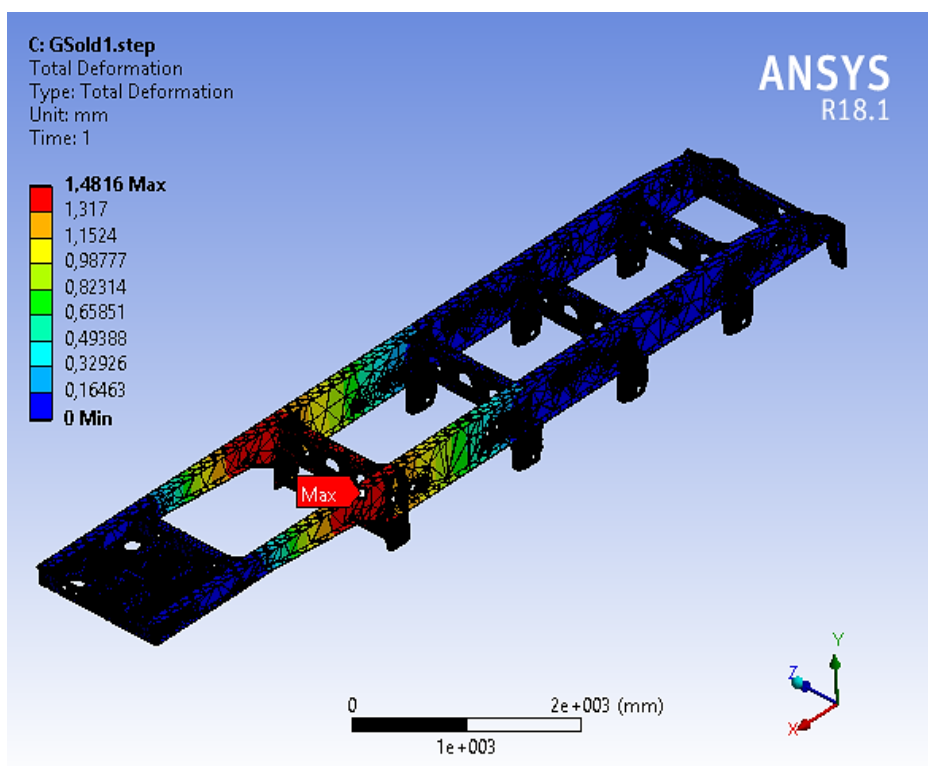

Şekil 11. Eski şasi modelinde meydana gelen deformasyon değeri 
Şekil 13'te görülen eski şaside meydana gelen maksimum gerilim değeri, yeni modelde önemli ölçüde düşürülmüş̧ür. Şekil 12 'deki yeni modellenen treyler şasisinin analiz sonucunda maruz kaldığı gerilim değeri $(292,47 \mathrm{MPa})$, şasi malzemesi olan S700MC çeliğinin literatürde bilinen dayanabileceği maksimum gerilim değerinden (700 MPa) \%58 oranında daha düşük ve 2,39 kat emniyetlidir.

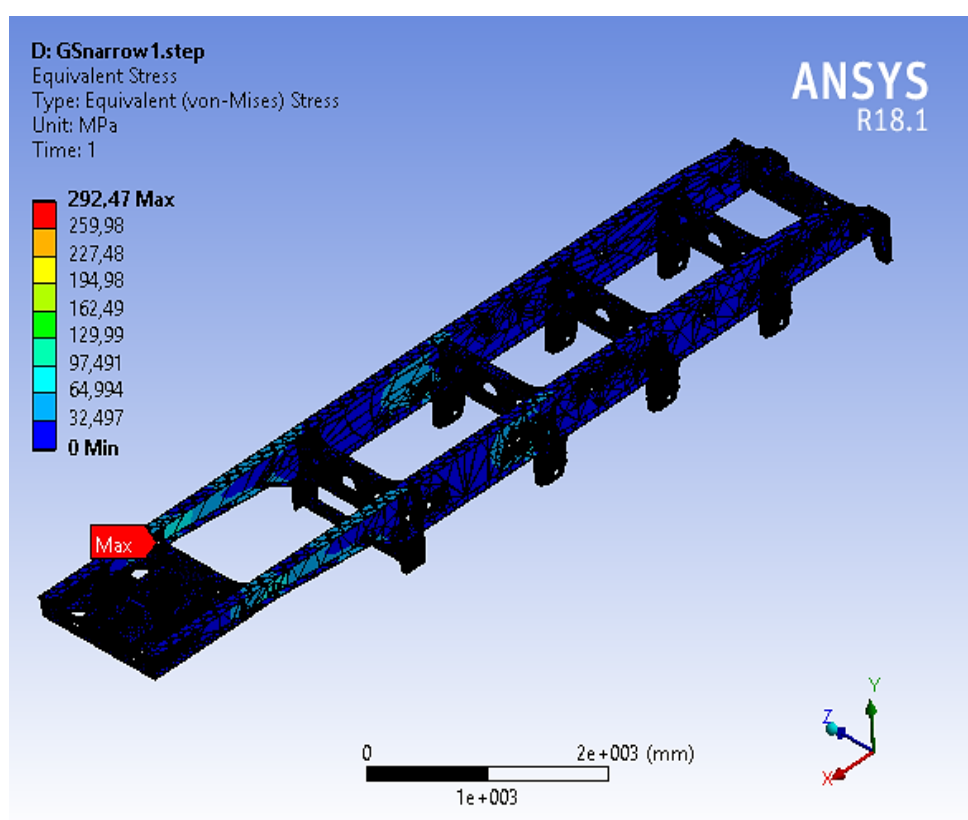

Şekil 12. Daraltılmışş şasi modelinde meydana gelen gerilim değeri

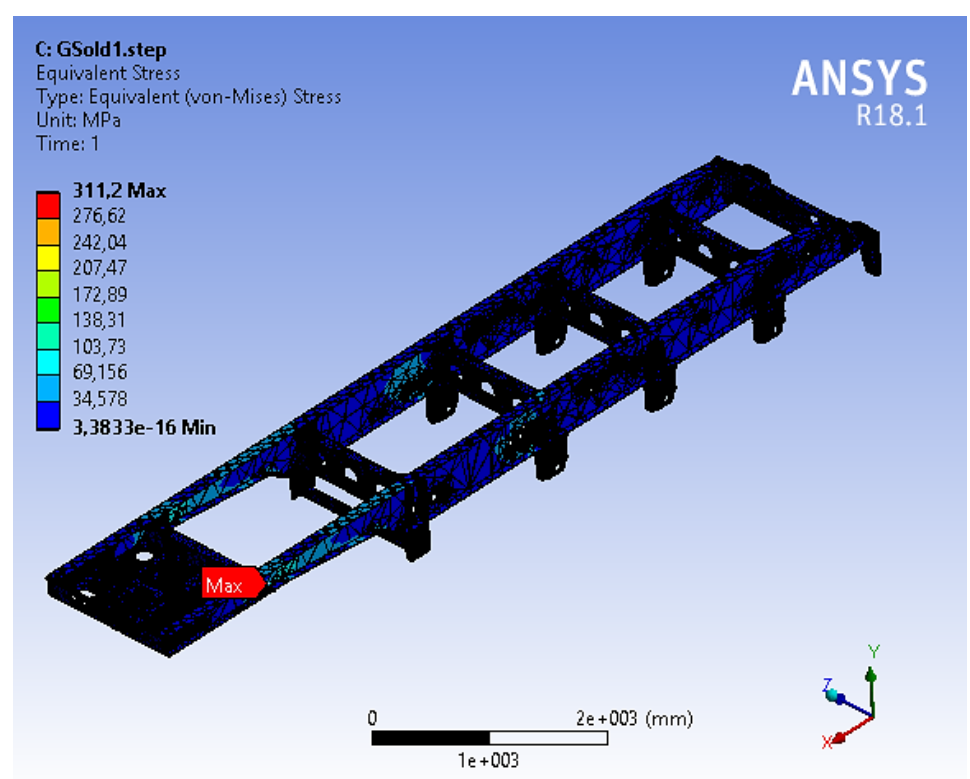

Şekil 13. Eski şasi modelinde meydana gelen gerilim değeri 


\section{SONUÇ}

Proje kapsamında daraltılan şasi parçaları üzerinde yapılan sonlu elamanlar yöntemi ile yapısal analizler sonucunda kritik noktalarda oluşan deformasyon miktarlarının \%10 oranında azaldığ 1 gözlemlenmiştir. Komple şasi modellerindeki incelemelere bakıldığında daraltılmış şaside $1,4875 \mathrm{~mm}$, eski şasi modelinde ise $1,4816 \mathrm{~mm}$ deformasyon değerleri gözlemlenmiştir. Deformasyon değeri oransal olarak çok düşük bir negatif değişimi gösterse de bu durum gerilme eğiliminde avantaja dönüşmektedir. Daraltılmış şasi modelinde meydana gelen maksimum gerilme değeri 292,47 MPa, eski şasi modelinde ise bu değerin 311,2 $\mathrm{MPa}$ olarak tespit edilmiştir. Böylece komple daraltılmış şasinin de analizler 1şı̆̆ında, eski modelden \%6 oranında daha az gerilime uğradığı saptanmıştır.

Bununla birlikte treyler şasisinin daraltılmış tasarımında değişen parçaları göz önüne alındığında en az \%7 oranında hafifleme söz konusudur. Bu bağlamda karayolları kullanımı ile çekici ve römork ömrünün uzatılmasına yönelik ilk adımlar atılmıştır.

\section{TEŞEKKÜR}

$\mathrm{Bu}$ çalışmanın gerçekleşmesinde; konu ve kaynak açısından desteklerini esirgemeyen Makinsan Treyler San. ve Tic. Ltd. Şti.'ye teşekkür ederiz.

\section{KAYNAKÇA}

1. Ozturk, F., Toros, S., Esener, E., Uysal, E. 2009. Otomotiv Endüstrisinde Yüksek Mukavemetli Çeliklerin Kullanımının İncelenmesi, TMMOB Makina Mühendisleri Odas1, 11. Otomotiv Sempozyumu, Bursa, Türkiye, 50(596), 44-49.

2. Kartal, Y., 2014. Taşıtlarda Akustik Performansı Gözetilerek Uygulanan Ağırlık Azaltma Yöntemleri, Yüksek Lisans Tezi, İstanbul Teknik Üniversitesi Fen Bilimleri Enstitüsü, İstanbul, 91.

3. Transport Statistics Great Britain, https://www.gov.uk/government/collections/tra nsport-statistics-great-britain, 17 Aralık 2020, 2012.

4. Mckinnon, A.C., 2006. Life Without Trucks: the Impact of a Temporary Disruption of Road Freight Transport on a National Economy. J. Business Logistics, 27(2), 227-251.

5. Galos, J., Sutcliffe, M., Cebon, D., Piecyk, M., Greening, P., 2015. Reducing the Energy Consumption of Heavy Goods Vehicles Through the Application of Lightweight Trailers: Fleet Case Studies, Transportation Research Part D: Transport and Environment. 41, 40-49.

6. Odhams, A.M.C., Roebuck, R.L., Lee, Y.J., Hunt, S.W., Cebon, D., 2010. Factors Influencing the Energy Consumption of Road Freight Transport, Proc. Inst. Mech. Eng. Part C-J. Mech. Eng. Sci. 224(9), 1995-2010.

7. Léonardi, J., Baumgartner, M., 2004. $\mathrm{CO}_{2}$ Efficiency in Road Freight Transportation: Status Quo, Measures, and Potential, Transport. Res. Part D: Transport Environ. 9(6),451-464.

8. Lai, W.T., 2015. The Effects of Eco-driving Motivation, Knowledge, and Reward Intervention on Fuel Efficiency, Transport. Res. Part D: Transport Environ. 34, 155-160.

9. Yang, C., McCollum, D., McCarthy, R., Leighty, W., 2009. Meeting an 80\% Reduction in Greenhouse Gas Emissions from Transportation by 2050: a Case Study in California, Transport. Res. Part D: Transport Environ. 14(3), 147-156.

10. Turner, M., Boyce, G., 2005. ROADLITEManufacture of a Lightweight, Cost-effective, Polymer Composite Road Trailer, JSAE Annual Congress, CrossRef Test Account Yokohama, Japonya, doi: 10.4271/2005-080199.

11. Publishable Final Activity Report D27 - Final Project Report, 2010. Development of Lightweight, Recyclable Thermoplastic Composite Semi-trailer and Boat Hulls with Enhanced Performance. Publishable Final Activity Report D27, EPL Composite Solutions, 46.

12. Verhaeghe, J., 2006. Introducing an Affordable Composite Trailer to a Conservative MarketReinforced Plastics, 20(5), 34-37. 
13. Jarvis, B., 2006. A Composite Glimpse of the Future. The Commercial Motor Magazine Archive. http://archive.commercialmotor.com/ article/12th-october-2006/52/a-compositeglimpse-of-the-future, 17 Ocak 2020.

14. Gardiner, G., 2014. Walmart Uses CFRP to Boost Efficiency: Composites World. https://www.gardnerweb.com/articles/walmartuses-cfrp-to-boost-efficiency, 18 Ocak 2020.

15. Kaiser, R., 2010. Thermosets and Thermoplastics set to Compete for Composite Trailer Market. European Plastics News, https:/www.avk-tv.de/files/pressclip/avk-pc/ 20101220_thermosets_and_thermoplastics_set to_compete_for_composite trailer.pdf, 18 Ocak 2020.

16. Galos, J., Sutcliffe, M., 2019. Material Selection and Structural Optimization for Lightweight Truck Trailer Design, SAE International Journal of Commercial Vehicles, 12(4), 281-297.

17. Şen, Ş., Yaşar, M., Koçar, O., 2018. Dorse Tasarımında Stres Dağılım Analizi ve Topoloji Optimizasyonu, Karaelmas Fen ve Müh. Derg., 8(1), 309-316.

18. Yıldırım, H.C., Marquis, G., Sonsino, C.M., 2015. Lightweight Potential of Welded Highstrength Steel Joints from S700 Under Constant and Variable Amplitude Loading by Highfrequency Mechanical Impact (HFMI) Treatment. Procedia Engineering, 101, 467-475.

19. BPW, 2010, Commercial Vehicle Catalogue 2010/2011- BPW. The Quality Factor 89, 118.

20. Ovalı, İ., Esen, C., 1999. Ansys Workbench, Altın Kitap, Ankara, 560. 